\title{
Editorial
}

\section{Measuring the Readiness for Change among Academics: The Case of Transforming Sri Lankan State Universities into 'World-class' Status}

\author{
PAP Samantha Kumara \\ Associate Professor in Marketing, Department of Marketing, Faculty of Management and Finance \\ University of Ruhuna
}

\begin{abstract}
Sri Lankan state universities are under the pressure of internationalization and achieving 'world-class' status. Attitudinal change among academics is imperative to transform state universities into 'world-class' status. There is a concern about the need for a paradigm shift of the state university academics to achieve international standards of 'world-class' universities. As such, this editorial note mainly focuses on providing a conceptual insight into the 'readiness for change' among state university academics, and on signifying a scale of measurement to facilitate the examination of how state university academics accept the transformations in progress to achieve 'world-class' university status. The suggested measurement scale consists of four dimensions, namely, 'appropriateness, administration support, change efficacy, and personal benefits, to examine the readiness for change among academics. Though readiness for change among the academics is not essentially sufficient to meet the internationalization and the achievement of the 'world-class' status of Sri Lankan state universities, a data driven longitudinal assessment will help higher education decision makers to take effective initiatives to transform Sri Lankan state universities into world-class status.
\end{abstract}

Keywords: Change, Higher Education, Internationalization, 'World-Class' Status

\section{Introduction}

Significant restructuring processes in hierarchical positioning have been initiated in the higher education systems of many countries in Europe and Asia to enhance their competitiveness in the global market (Deem, Mok and Lucasa, 2008). Sri Lanka is also striving to emerge as the knowledge hub of the South Asian region, by elevating its state university system to 'world-class' status through restructuring processes (Chanaka and Samantha, 2016). Restructuring and internationalization of universities require systematic review, analysis and researching the way forward for the country with learnt experience, competition, local values and needs (Gamage, 2012).

Restructuring processes towards 'world-class' status will lead Sri Lankan universities to be at a higher global rank. However, the attitudinal change among organizational members is imperative, with all other initiatives taken towards transforming state universities to gain 'world-class' status. Unless the key personalities (i.e. academics) are adapted to the required system, there will be difficulties in reaching the target of being 'world-class.' The direction towards 'world-class' status, will be smoothed by the 'readiness for change among the academics'. Creating a culture that values and supports international perspectives is needed, since without a strong belief system and a supportive culture, restructuring of universities will never be realized (Qiang, 2003). 'Readiness' is a key factor that affects the success of the paradigm shift towards achieving 'world-class' status through internationalization of universities. Thus, internationalization requires a major change in the minds of the academics in state universities. *corresponding author:, samanthak@badm.ruh.ac.lk (iD) https://orcid.org/0000-0001-8865-9608 
The key challenge of change lies in gaining employees' willingness to commit to the change effort (Soumyaja, Kamlanabhan and Bhattacharyya, 2015). Especially the academics, as the key to deliver effective study programs and to develop effective research culture in the universities, should be ready to change their practices to match international standards and qualities of higher education. The internationalization of Japanese higher education has generally indicated a process of change for the better from an imperfect state that did not meet international needs (Horie, 2002).

This editorial note endeavors to focus on the need for a paradigm shift of the state university academics towards international standards of 'world-class' universities. As such, this editorial note is significant as it provides conceptual insight into the 'readiness for change' among state university academics, and the suggested 'scale' facilitates the comprehension of how state university academics accept the on-going changing practices in order to achieve 'world-class' university status.

\section{Internationalization of Higher Education and World-class University}

Higher education can no longer be perceived in a strictly national context (Qiang, 2003). Globalization has provided a wake-up call to higher educational institutes, signaling an urgent need to address critical issues such as structures, missions, processes, programmes, and leadership (Hanson, 2012). It indicates that 'internationalization' has been a global concept and 'internationalization' of universities has recently become a keyword in many countries (Toyoshima, 2007). Furthermore, internationalization of higher education includes the policies and practices undertaken by academic systems and institutionsand even individuals - to cope with the global academic environment (Altbach and Knight, 2007). Internationalization of higher education has been influenced by the globalization of economies and societies and the increased importance of knowledge (De Wit and Hunter, 2015).

'Internationalization of higher education' and the 'world-class' university are seen as very different, yet much related processes. Internationalization assumes a more integral process-based approach, aimed at a better quality of higher education and competencies of staff (De Wit, 2017). Thus, the internationalization of higher education institutes has led to the phenomenon of 'world-class' universities. Hence, the notion of 'world-class' university in recent years has become a key word, and is now firmly embedded in the higher education policies and strategies of a range of nations (Deem et al., 2008). The 'world-class' status of a university is determined by the international recognition. What is critical is that the international dimension relates to all aspects of education and the role that it plays in society (Knight, 2004).

Many universities in America, Europe and Asia Pacific region are already recognized as 'world-class' universities, and countries in the Middle East, Africa, and South Asia are now taking initiatives to gain 'world-class' status to their universities. Accordingly, Sri Lankan state universities are under the pressure of internationalization and achieving 'world-class' status. Consequently, Sri Lankan higher education system has to undergo a dramatic change to meet the modern-day requirements of higher education. The state universities have to initiate reforms, such as revising and introducing new study programmes, reforming the teaching and learning environment, promoting a culture of research and publications, developing industry partnerships, and attracting foreign students. Transformation through restructuring processes is a prerequisite to uplift the academic excellence to achieve 'world-class' status.

\section{Readiness for Change among Academics to Achieve 'World-class' Status}

Sri Lankan state universities share a unique academic culture. The university system in Sri Lanka went through planned, as well as unplanned, changes since the country had gained independence from Britain at the end of the 1940s. The academics in Sri Lankan universities share both Western norms as well as traditional values of Sri Lankan culture. Education was considered a 'public good', rather than a source of revenue for the country. For a long period, university education has been given free to all entrants to the state university system. Therefore, many students and academics consider university education a 'public good', rather than a 'business.' Hence, upgrading Sri Lankan universities to 'world-class' status requires a paradigm shift among many people, particularly among the state university academics.

The readiness of the academics in the state universities to become a 'world-class' university is decisive. Internationalization is viewed as an organizational adaptation (Bartell, 2003). Without proper adaptation and careful contextualization, we might easily encounter problems (Deem et al., 2008). Transformation and restructuring process should consider a global market place for students, and faculty; highly educated personnel and global reach of the new Internet-based technologies (Altbach, 2002). 
This transformation in higher education may face new trends, challenges, and opportunities with crossnational implications (Gamage, 2012).

\section{Suggested Scale of Measures of the Readiness for Change among Academics}

The factor structure derived by Holt et al., (2007) has suggested measuring the readiness for change among the academics, and it includes four factors (Appropriateness, Administration Support, Change Efficacy, and Personal Benefits) to measure the readiness for change. The total scale consists of 26 variables, the validity of which was established. According to Holt et al., (2007) understanding academics' perception of the appropriateness of the change, their beliefs on administration support, feelings of their capability to successfully implement the change, and perception of personal benefits would provide important insights for change agents (i.e. Vice Chancellors, Deans, Heads, etc...in higher education context) to take effective action. Therefore, the suggested measure will be useful to examine the readiness for change among the academics of Sri Lankan universities. However, as the variables under each dimension are not directly related to the internationalization of higher education institutes, they are to be re-written to focus on internationalization to achieve 'world-class' status for Sri Lankan universities. Further, the five-point Likert scale ranging from 'strongly agree' (5) to 'strongly disagree' (1) can be used to measure the responses (Malhotra and Dash, 2010). The suggested variables of each dimension are given in Table 1.

Table 1: Scale of measures of the readiness for change for internationalization among the academics of state universities

\section{Factor 1: Appropriateness}

I think that our university will benefit from internationalization.

It doesn't make much sense for us to internationalize the university.

There are legitimate reasons for us to internationalize the university.

Internationalization will improve the university's overall efficiency.

There are several rational reasons for the internationalization of the university.

In the long run, I feel it will be worthwhile for me, if the university is internationalized.

Internationalization of the university makes my job easier.

When the university is internationalized, I don't believe that there is anything for me to gain.

The time we spend on internationalization should be spent on something else.

Internationalization matches the priorities of the university.

\section{Factor 2: Administration Support}

University administration has encouraged all of us to embrace internationalization.

University's top decision-makers have extended all their support to internationalize the university.

Every senior administrative officer (i.e. VC, DVC, Registrar, Deans, and Heads etc...) has stressed the importance of this change.

The Vice-chancellor of the university is committed to this change.

I think we are spending a lot of time on internationalization when the senior administration doesn't even want it implemented.

University administration has sent a clear signal that the university is going to move towards internationalization.

University administration has taken the necessary steps to make us aware of the internationalization of the university.

\section{Factor 3: Change Efficacy}

I do not anticipate any problems adjusting to the work I will have when the university is internationalized.

I don't think I can do some tasks that will be required when we change, well.

When we internationalize the university, I feel I can handle it with ease.

I have the skills that are required to make the internationalization work.

When I set my mind to it, I can learn everything that will be required when our university is internationalized.

My past experience makes me confident that I will be able to perform successfully after the university is internationalized.

\section{Factor 4: Personal Benefits}

I am worried that I will lose some of my status in the organization when the university is internationalized. Internationalization of the university will disrupt many of the personal relationships that I have developed. My future in this job will be limited because of the internationalization of the university.

Source: adapted by Holt et al., (2007) 


\section{Concluding Remarks}

Internationalization, as a worldwide phenomenon, is a major trend in higher education and it is widely misunderstood (Altbach, 2002). The changes required in the university system for internationalization and obtaining 'world-class' status is provocative since the readiness for change among the academics of the system is not well addressed. The achievements of the programmes and projects conducted for internationalization of the state university system in Sri Lanka seem far behind the expected results. This has been extensively discussed in most of the progress reviews and evidenced with the insufficient performances towards being international and 'worldclass' level.

A conceptual understanding of the readiness for change among the academics towards internationalization, and subsequently garnering 'world-class' status have become contemporary needs to comprehend the manner of implementation of strategic approaches. This will better lead the understanding of the context of where the Sri Lankan state university academics are, and the nature of initiatives to be taken to acquire 'world-class' status. Without the contribution of educational vision which focuses on the 'world-class' status, successful achievements in state universities would be challenging and perhaps impossible. The suggested scale gauges the readiness for organizational change at an individual level, enabling the higher education decision-makers to understand the strategic approaches required. Thus, explicit changes in affective, cognitive, and behavioral reactions to the change made by the higher education decision-makers can be examined by using the suggested scale, since the quest for building internationalized universities with world-class research and teaching excellence should go together with the readiness for change among the academics. Inevitably, there are barriers linked to institutional issues of language proficiency and the nature of academic engagement and reward, to be overcome (De Wit and Hunter, 2015).

The dimension of 'appropriateness' addresses the factuality of internationalization of the university. Whether the process of internationalization is supported by the higher authority of the university (i.e. administration) is addressed by the dimension of 'administration support'. The 'change efficacy' dimension addresses the readiness of the academics to take the journey of internationalization with their knowledge, skills and attitudes. The 'personal benefits' dimension is directed to discover whether the internationalization disrupts the academics' duties and responsibilities. Internationalization is a process to improve the goals, functions, and delivery of higher education, and thus to upgrade the quality of education and research (De Wit, 2017). Accordingly, the dimensions of the suggested measure have addressed the key facets of upgrading the quality of higher education. Thereupon, the suggested measure has the potential to examine the behaviors of the academics in terms of their readiness for change. Identifying the types of behaviors academics display should be the key to direct them towards 'world-class' status through internationalization of state universities. Longitudinal assessment of the change behavior of the academics will allow higher education decision makers to understand and increase the effectiveness of the strategies taken over time. This will further allow the systematization of the transformation process of internationalization, and to make deliberate, explicit alignments to the organizational structure, academic programs, research initiatives, and incentive schemes.

It is worthy to note that readiness for change among the academics is not essentially sufficient to meet internationalization and to achieve 'world-class' status of Sri Lankan state universities. It is also required to measure the readiness for change among the stakeholders of the Sri Lankan state universities, and take initiatives accordingly. In addition, new variables maybe added to the suggested measure of the readiness for change among academics.

\section{References}

Altbach, P. G. (2002). Perspectives on international higher education. Change: The Magazine of Higher Learning, 34(3), 29-31.

Altbach, P. G., \& Knight, J. (2007). The internationalization of higher education: Motivations and realities. Journal of studies in international education, 11(3-4), 290-305.

Bartell, M. (2003). Internationalization of Universities: A University Culture-based Framework, Higher Education, 45, 43-70.

Chanaka Ushantha, R. A., \& Samantha Kumara, P. A. P. (2016). A quest for service quality in higher education: Empirical evidence from Sri Lanka. Services Marketing Quarterly, 37(2), 98-108.

De Wit, H. (2017). Global: Internationalization of Higher Education: Nine Misconceptions: International Higher Education, Summer 2011, Number 64. In Understanding higher education internationalization (9-12). Brill Sense. 
De Wit, H., \& Hunter, F. (2015). The future of internationalization of higher education in Europe. International higher education, 83, 2-3.

Deem, R, Mok, H. H., \& Lucasa, L. (2008). Transforming Higher Education in Whose Image? Exploring the Concept of the 'World-Class' University in Europe and Asia, Higher Education Policy, 21, 83-97.

Gamage, S. (2012). Internationalization of higher education (IHE) in selected Asian countries: contextual issues, trends, and questions/options for Sri Lanka. In Workshop Proceedings, University Grants Commission, Sri Lanka.

Hanson, K. T. (2012). Rethinking institutional leadership in a globalized era: strategic imperatives for higher education. In Workshop Proceedings, University Grants Commission, Sri Lanka.

Holt, D. T., Armenakis, A. A., Feild, H. S., \& Harris, S. G. (2007). Readiness for organizational change: The systematic development of a scale. The Journal of Applied Behavioural Science, 43(2), 232-255.

Horie, M. (2002). The internationalization of higher education in Japan in the 1990s: A reconsideration, Higher Education, 43, 65-84.

Knight, J. (2004). Internationalization Remodeled: Definition, Approaches, and Rationales, Journal of Studies in International Education, 8(1), 5-31.

Malhotra, N. K., \& Dash, S. (2010). Marketing research: An applied approach. Dorling Kindersely (India) Pvt.Ltd.

Qiang, Z (2003). Internationalization of Higher Education: towards a conceptual framework, Policy Futures in Education, 1(2), 248-270.

Soumyaja, D., Kamlanabhan, T. J., \& Bhattacharyya, S. (2015). Antecedents of employee readiness for change: mediating effect of commitment to change. Management Studies and Economic Systems, 54(2518), 1-15.

Toyoshima, M. (2007). International strategies of universities in England. London Review of Education, 5(3), 265-280. 